\title{
A Etnomodelagem na formação de professores: uma análise a partir de produções recentes
}

\author{
José Lucas Matias de Eça \\ Zulma Elizabete de Freitas Madruga
}

\begin{abstract}
Resumo: Este artigo objetiva apresentar uma análise crítica a partir do aprofundamento teórico sobre Etnomodelagem e do mapeamento de pesquisas recentes. Trata-se de uma pesquisa qualitativa, onde foi utilizado o Mapeamento na Pesquisa Educacional. Como respaldo para as discussões, buscou-se no Catálogo de Teses e Dissertações da Coordenação de Aperfeiçoamento de Pessoal de Nível Superior e na Biblioteca Digital de Teses e Dissertações, pesquisas sobre Etnomodelagem. Foram encontradas três pesquisas que compuseram o corpus de análise. Dada a quantidade reduzida, foram realizadas outras buscas que pudessem subsidiar as discussões. Os resultados apontam para uma carência na utilização desta alternativa na formação de professores. Afinal, a Etnomodelagem está a serviço de uma educação que visa a diluição das diferentes formas de desigualdades sociais que ainda perduram na sociedade atual.
\end{abstract}

Palavras-chave: Educação Matemática. Etnomodelagem. Formação de professores. Mapeamento.

\section{Ethnomodelling in teacher education: an analysis based on recent productions}

José Lucas Matias de Eça Mestre em Educação em Ciências e Matemática pela Universidade Estadual de Santa Cruz (UESC), campus llhéus. Professor da rede municipal de ensino, Cairú, Bahia, Brasil. https://orcid.org/0000-0001-5848-2100 $\triangle$ lucasceeft@hotmail.com

Zulma Elizabete de Freitas Madruga Doutora em Educação em Ciências e Matemática (PUCRS), campus Rio Grande do Sul. Professora da Universidade Federal do Recôncavo da Bahia (UFRB), Amargosa, Bahia, Brasil. D. htp://orcid.org/0000-0003-1674-0479 $\square$ betefreitas.m@gmail.com Recebido em 26/02/2021 Aceito em 08/03/2021 Publicado em 24/03/2021
Abstract: This essay aims to present a critical analysis from the theoretical deepening study on Ethnomodelling and the mapping of recent researches. It is a qualitative research, for which Mapping was used in Educational Research. As a support for the discussions, a research on Ethnomodelling was carried out in the Catalog of Theses and Dissertations of the Coordination for the Improvement of Higher Education Personnel and in the Digital Library of Theses and Dissertations. Three researches were found that comprised the corpus of analysis. Given the reduced quantity, other searches were carried out that could support the discussions. The results point to a lack of use of this alternative in teacher training. After all, Ethnomodelling is at the service of an education that seeks to dilute the different forms of social inequality, that still persist in today's society.

Keywords: Mathematical Education. Ethnomodeling. Teacher Education. Mapping.

\section{Etnomodelación en la formación del profesorado: un análisis de las producciones recientes}

Resumen: Este artículo tiene como objetivo presentar un análisis crítico desde la profundización teórica sobre la Etnomodelación y el mapeo de investigaciones recientes. Es una investigación cualitativa donde se utilizó el Mapeo en la Investigación Educativa. Como apoyo a las discusiones, se realizó una investigación sobre Etnomodelación en el Catálogo de Tesis y Disertaciones de la Coordinación para la Perfeccionamiento del Personal de Educación Superior y en la Biblioteca Digital de Tesis y Disertaciones. Se encontraron tres investigaciones que formó el corpus de análisis. Dada la cantidad reducida, se llevaron a cabo otras búsquedas que podrían apoyar las discusiones. Los resultados apuntan a una falta de uso de esta alternativa en la formación docente. Después de todo, la Etnomodelación está al servicio de una educación que busca diluir las diferentes formas de desigualdad social, que aún persisten en la sociedad actual.

Palabras clave: Educación Matemática. Etnomodelación. Formación de profesores. Mapeo. 


\title{
1 INTRODUÇÃO
}

O modelo de ensino de Matemática tradicionalmente realizado no ambiente escolar é caracterizado pela transmissão de conhecimento, pautado no enaltecimento da técnica operatória ou algorítmica, ao invés do entendimento de seu uso, e pouco contribui para o desenvolvimento de ações que visam a formação de indivíduos capazes de assumir uma criticidade frente ao mundo (BRASIL, 2017). Nesse sentido, Rosa e Orey (2003, p. 2) enfatizam que:

\begin{abstract}
A Educação Matemática tradicional visa a transmissão de uma determinada quantidade de técnicas que são utilizadas em situações artificiais e que são apresentadas como problemas. Os problemas são formulados artificialmente e somente auxiliam na memorização de certas habilidades pelos alunos. Estes tipos de problemas e as técnicas utilizadas na resolução dos mesmos são geralmente tediosos, desinteressantes, obsoletos, e não possuem relação com o mundo externo e contemporâneo. Estas características da Educação Matemática tradicional são responsáveis pela diminuição do interesse, do rendimento e pelo baixo grau de satisfação escolar que os alunos possuem.
\end{abstract}

Logo, perguntas como "para que devemos estudar isso?" ou "por que estudar matemática?" se tornam frequentes nas salas de aula de matemática por todo o Brasil. A falta de respostas para esses questionamentos, associada à forma quase sempre mecânica e descontextualizada com que são abordados os objetos de conhecimento matemáticos, contribuem para esse cenário preocupante em que a educação brasileira se encontra, no que tange ao ensino e a aprendizagem de Matemática.

Essa postura político-pedagógica que caracterizou o ensino de matemática no Brasil produziu índices insatisfatórios em avaliações externas, como no Programa Internacional de Avaliação de Estudantes - PISA, por exemplo, cujo objetivo é revelar indicadores que podem contribuir para a melhoria do Ensino Básico dos países participantes do estudo. O Brasil se configurou - na proficiência de Matemática - na $70^{\text {a }}$ (septuagésima) posição no ranking de um universo de 79 países. 0 estudo da pesquisa ainda revela que $68,1 \%$ dos estudantes brasileiros, com faixa etária de 15 anos, não possuem nível básico de Matemática (BRASIL, 2019).

Outro dado que revela preocupação nesse cenário é apresentado pelo Instituto Nacional de Estudos e Pesquisas Educacionais (INEP), que em 2019 realizou um balanço do Sistema Nacional de Avaliação da Educação Básica (SAEB) dos últimos 10 anos. Os resultados mostram uma queda acentuada no desempenho dos estudantes, tanto no componente curricular de Língua Portuguesa quanto no de Matemática. Para endossar essa perspectiva, outro dado revela preocupação em relação ao baixo índice de aproveitamento dos estudantes concluintes da Escola Pública em 2018, na prova objetiva do Exame Nacional do Ensino Médio - ENEM (BRASIL, 2018). Contexto que provoca uma reflexão sobre dois apontamentos iniciais: i) formação inicial e continuada de professores; e ii) as práticas pedagógicas adotadas em sala de aula. 
Desse modo, os dados sugerem uma reestruturação de um novo currículo, entendido aqui, de acordo com Macedo (2007), para além de um referencial (re)produtivista, que se resume à prescrição de conteúdo. Em outras palavras, concebido como um artefato sociocultural de interação dinâmica com os campos de vivência (constituindo o saber, o saber fazer e o saber ser). 0 currículo deve contemplar os saberes-fazeres necessários à educação dos estudantes, de modo a ser integrador com suas vivências, a fim de oportunizar uma construção de identidades.

A escola inserida nessa conjuntura, construída e alinhada com os dispositivos legais (BRASIL, 1996, 1998, 2007, 2017) que norteiam as diretrizes pedagógicas no país, se torna um importante instrumento político-social contemporâneo na formação de cidadãos que (re)conhecem seu lugar e sua função diante da sociedade na qual estão inseridos. Para isso, é necessário que a escola invista em ações que promovam uma conscientização cidadã (alicerçada em preceitos que visam 0 desenvolvimento ético, autônomo, responsável, reflexivo, cidadão, crítico e criativo do educando) e se distancie das amarras tradicionais que limitam as possibilidades de exploração de outros saberes, que não exclusivamente aqueles ditos "escolarizados".

Com isso, o professor, integrante crucial desse contexto, consciente de uma compreensão histórica de seu papel, enfrenta o desafio de se reinventar periodicamente, mobilizando mecanismos disponíveis na esfera teórico-prática (FREIRE, 1996). Destarte, o professor, dedicado à construção desse processo educativo, deve conscientemente buscar um repertório de conhecimentos de diversas áreas, que supere a subordinação de transmissão de conhecimentos, visando potencializar essa questão (PONTE, 1999). Faz-se necessário viabilizar a operacionalidade coletiva (ou colegiada), pautada na dialogicidade, com a troca de experiências entre os distintos agentes do espaço escolar, sobretudo, com a troca de saberes entre o mundo escolar e o mundo extraescolar (ROSA; OREY, 2017).

Para atender a esses pressupostos, deve-se conduzir a postura político-pedagógica da escola de tal maneira que perpasse os caminhos de construção de saberes que levem apenas ao objeto matemático, ocorrendo a partir dos estudos intervencionistas exploratórios no meio social, para que se produzam saberes matemáticos. Percebe-se, nesse âmago, a interação das questões sociais emergentes do cotidiano sob as lentes do conhecimento matemático, e isso, segundo Rosa e Orey (2003), é se aproximar da Etnomodelagem, uma alternativa pedagógica resultante do entrelaçamento entre a Modelagem Matemática e a Etnomatemática.

A Etnomodelagem se constitui um marco político-pedagógico no enfrentamento das desigualdades sociais que promovem injustiças de diferentes naturezas. Por isso, as dimensões que sustentam as bases desse programa de pesquisa, que tem em seu escopo, dentre outros encaminhamentos, uma posição contrária à vertente que acredita possuir apenas uma só matemática. $A$ 
pluralidade de produção de saberes matemáticos se traduz como sendo um dos(as) lemes/bússolas que direcionam as discussões acerca da valorização de outros saberes germinados em seios contrahegemônicos, delineando-se, portanto, como um importante mecanismo de enfrentamento das variadas formas de preconceito.

Lógica essa que se coaduna com a concepção apresentada/refletida no Documento Curricular Referencial da Bahia - DCRB (BRASIL, 2019, p. 35), ao endossar o compromisso político-social-ético da escola em promover um espaço que dê visibilidade/voz aos grupos oprimidos, por meio da

\begin{abstract}
[...] valorização da diversidade de saberes e vivências culturais que tratam do mundo do trabalho, a partir das escolhas, fruto dos seus projetos de vida; cuidado de si mesmo, dos outros e do planeta; autoconhecimento e cuidado com a saúde física e emocional; exercício de empatia, diálogo, resolução de conflitos e cooperação; ação pessoal e coletiva com autonomia, responsabilidade, flexibilidade, resiliência e determinação, tudo isso numa perspectiva inclusiva, que envolve as relações étnico-raciais, de gênero, regional, linguística e religiosa, contemplando as dimensões da integralidade e da identidade/diferença, que se referem ao pertencimento e empoderamento das singularidades humanas e inovação, as quais envolvem tanto o contexto do mundo digital quanto pessoal, o saber olhar para si e para o desenvolvimento das competências socioemocionais.
\end{abstract}

Com efeito, sublinha-se a relevância dessa alternativa na prática docente, tendo como uma das bandeiras a de valorizar os saberes-fazeres que são historicamente invisibilizados pelas classes opressoras por meio da matemática. Desse modo, este trabalho possui a intencionalidade de responder à seguinte questão: existem formações continuadas que têm como fundamentação a Etnomodelagem e, se há, como se concebe? Surgindo, por consequência, o objetivo de apresentar uma análise crítica a partir do aprofundamento teórico sobre Etnomodelagem e do mapeamento de pesquisas recentes, na busca por verificar as possibilidades de essa alternativa metodológica configurar como subsídio para a formação de professores de matemática.

\title{
2 ETNOMODELAGEM
}

A atual conjuntura de mundo globalizado tem exigido do cidadão uma interatividade com os mecanismos que compõem o sistema, sobretudo de maneira consciente e crítica. Dessa forma, deve-se "considerar que o professor de matemática precisará dar conta de uma nova forma de racionalizar advinda das questões que se fizeram notar na virada do século XIX para o século XX, bem como das contradições econômicas, sociais e culturais que se fizeram na virada do século XX para o Século XXI. (CALDEIRA, 2009, p. 2)

O sentido de global aqui entendido está para além de um contexto de lugar; refere-se a um conjunto de partes que, em conexão, representam o todo. Sendo assim, concorda-se com Morin (2000, p. 37) quanto ao seguinte entendimento: 
O global é mais que o contexto, é o conjunto das diversas partes ligadas a ele de modo interretroativo ou organizacional. Dessa maneira, uma sociedade é mais que um contexto: é o todo organizador de que fazemos parte. 0 planeta Terra é mais do que um contexto: é o todo ao mesmo tempo organizador e desorganizador de que fazemos parte. $O$ todo tem qualidades ou propriedades que não são encontradas nas partes, se estas estiverem isoladas umas das outras, e certas qualidades ou propriedades das partes podem ser inibidas pelas restrições provenientes do todo.

Para D'Ambrosio (2020), o movimento de globalização e internacionalização da educação favorece o reforço de reflexões locais. Sobre os efeitos da globalização, Rosa e Orey $(2017$, p. 8) afirmam que:

A globalização reforça a abordagem utilitarista da matemática escolar predominante nas escolas. Essa abordagem propiciou a transmissão de ideologias matemáticas difusas, bem como a noção de que a matemática escolar é uma força cultural homogeneizadora, um filtro para a manutenção do status e um instrumento de poder.

Essas constantes mudanças globais, que impactam os modos de relações sociais, têm conduzido governos a implementarem ações no âmbito educacional, para assim acompanhar os aspectos oriundos dessas mudanças e não se isolar em seu próprio mundo. Dessa forma, os documentos que norteiam as diretrizes da educação brasileira, na tentativa de se buscar uma equidade educativa, vêm sendo reformulados. Um exemplo dessa mudança está na promulgação da Base Nacional Comum Curricular - BNCC, que garante o direito ao conjunto orgânico e progressivo de aprendizagem essencial ao educando, não mais centrado apenas no objeto do conhecimento, mas agora por meio de habilidades e competências (BRASIL, 2017).

A implantação desse documento provocou uma série de mudanças nas esferas que compõem o sistema educacional, a saber: nos referenciais curriculares das redes, nas políticas públicas referentes a avaliações (internas e externas) e a materiais didáticos, currículo das escolas e formações docentes (iniciais e continuadas). Isso implica, por um lado, um conjunto de saberes comuns que todos, independentemente do lugar onde estejam, têm direito de aprender. Por outro lado, a abertura dos entes federativos, criando seu próprio conjunto de saberes que contemplam e valorizam aspectos socioculturais de sua localidade.

Com efeito, vislumbra-se, com tais assertivas, uma diminuição das desigualdades que demarcam a educação no país por meio de ações legitimadas democráticas, colocando-se o educando no centro do processo de ensino e de aprendizagem. Assim, a comunidade escolar, entendida como um espaço de formação permanente, precisa continuamente rever suas práticas educacionais e seus modelos de ensino, tendo em vista o compromisso social frente tais demandas.

Esse aspecto de continuidade na formação se aproxima da percepção, segundo Freire (1996), do ser inacabado, que tendo consciência disso procura estabelecer mecanismos que visam uma busca 
permanente da aprendizagem. Afinal, "é na inconclusão do ser, que se sabe como tal, que se funda a educação como processo permanente. [...] Não foi a educação que fez mulheres e homens educáveis, mas a consciência de sua inconclusão é que gerou sua educabilidade" (FREIRE, 1996, p. 57). Entretanto, é necessário ir além da simples constatação de ser incompleto como docente, visto que, de acordo com Freire (1992, p. 138) "[...] a pura percepção da inconclusão, da limitação, da possibilidade, não basta. É preciso juntar a ela a luta política pela transformação do mundo. A libertação dos indivíduos só ganha profunda significação quando se alcança a transformação da sociedade".

Essa leitura de mundo requer, além da utilização do conhecimento matemático, 0 reconhecimento de outras formas de se produzir matemática, a não ser aquelas estudadas no âmbito escolar, isto é, os saberes locais e globais, respectivamente. Nesse sentido, os membros de diversos grupos sociais carregam em suas práticas diárias locais uma gama de significados matemáticos, tendo influência ou não do conhecimento global. Esse reconhecimento e interação entre os saberes locais e globais proporcionam o desenvolvimento de uma globalização localizada (ROSA; OREY, 2017). Aliamse a isso duas competências específicas de Matemática da BNCC (BRASIL, 2017, p. 265), ao considerar que se deve:

Reconhecer que a Matemática é uma ciência humana, fruto das necessidades e preocupações de diferentes culturas, em diferentes momentos históricos, e é uma ciência viva, que contribui para solucionar problemas científicos e tecnológicos e para alicerçar descobertas e construções, inclusive com impactos no mundo do trabalho.

Dessa forma, é importante desenvolver e/ou discutir projetos que abordem, sobretudo, questões de urgência social, com base em princípios éticos, democráticos, sustentáveis e solidários, valorizando a diversidade de opiniões de indivíduos e de grupos sociais, sem preconceitos de qualquer natureza. Ainda, propostas que contemplem o desenvolvimento de competências que convirjam para a construção de um ambiente formativo que promova criticidade e consciência ativa e participativa nos meandros das discussões sociais nas quais os estudantes estejam inseridos.

Na busca por uma alternativa metodológica que atenda esses pressupostos, alinhada com as diretrizes pedagógicas contidas nos documentos oficiais, a Etnomodelagem candidata-se como possibilidade para o processo de ensino e aprendizagem de Matemática, principalmente por estimular a aproximação entre os conhecimentos vistos na escola e o cotidiano dos aprendizes.

É salutar enfatizar que a Etnomodelagem é relativamente nova, tendo como marco um artigo publicado em 2003 por Milton Rosa e Daniel Clark Orey, intitulado "Vinho e queijo: Etnomatemática e Modelagem!"1, produto científico resultante de uma reflexão provocada por Scandiuzzi (2002), ao

\footnotetext{
${ }_{1}^{1}$ Disponivel em: https://www.periodicos.rc.biblioteca.unesp.br/index.php/bolema/article/view/10541. Acesso em: 4 jan. 2021.
} 
mencionar a não aproximação entre a Modelagem Matemática (MM) e a Etnomatemática, de tal modo que não fosse possível utilizá-las conjuntamente.

Segundo Scandiuzzi (2002), essas tendências, quando comparadas, possuem características distintas, principalmente em suas vias práticas. Esse estudioso argumenta que o modelador matemático identifica uma situação problema, em seguida se aproxima dos elementos que compõem o fenômeno estudado e, por fim, mobiliza mecanismos para a sua resolução. Por sua vez, um pesquisador da Etnomatemática busca explorar e valorizar as formas distintas de produzir conhecimento matemático em localidades socioculturais diversas. Caracterizam-se, nesse prisma, como duas concepções teóricopráticas divergentes, não havendo, assim, proximidades entre si (SCANDIUZZI, 2002).

Como já exposto, para Rosa e Orey (2003; 2006; 2010; 2014; 2017) é possível trabalhar concomitantemente com a Etnomatemática e a MM, criando um outro conceito teórico que, sobremaneira, tem como escopo a valorização do saber local (identificado a partir das práticas diárias) construído pelos membros de grupos sociais por meio da matemática que, por sua vez, serve de instrumento político no desenvolvimento de consciência identitária de aspectos inerentes às práticas socioculturais de sua localidade. Isto é, segundo Rosa e Orey $(2017$, p. 8), esse procedimento de "[...] tradução implica em um desempenho holístico que incorpora a globalização e a localização, expandindo o fluxo intracultural, que busca a valorização e o respeito do conhecimento matemático desenvolvido pelos membros de grupos culturais distintos".

Dessa maneira, a tradução ética dos saberes-fazeres dos membros pertencentes a distintos grupos culturais para a linguagem matemática traz consigo elementos que ultrapassam os limites da concepção da produção matemática centrada em si mesma e dialoga com fatores antropológicos culturais que fundamentam a Etnomodelagem. Afinal, de acordo com Rosa e Orey (2010), a Etnomodelagem se define como a interseção entre três campos de conhecimento, a saber: Modelagem Matemática, Etnomatemática e Antropologia Cultural.

Por meio do dinamismo cultural, esse processo interativo entre esses diferentes campos de conhecimento com os membros externos ou os observadores de fora (outsiders) e os membros internos ou os observadores de dentro (insiders) do grupo social investigado, produzem saberes de cunho matemático que estão presentes nos conhecimentos tácitos ${ }^{2}$ de determinados grupos, que devem ser respeitados e valorizados de forma congruente aos saberes já constituídos pela academia. Encorpando essa ideia, os autores enfatizam que os

\footnotetext{
2 Referem-se às "emoções, experiências, introspecções, intuições, observações e informações internalizadas, que são desenvolvidas por meio da compreensão dos fenômenos que são desencadeadas no cotidiano" (ROSA; OREY, 2017, p. 11).
} 
[...] investigadores e educadores podem se deparar com um conjunto de características relacionadas com as ideias, os procedimentos e as práticas matemáticas que são distintas daquelas frequentemente estudadas na Academia. Esse conjunto de características pode ser traduzido academicamente por meio de um processo denominado Etnomodelagem. (ROSA; OREY, 2014, p. 134)

Para que esse contexto se efetive, é necessário, no entanto, que haja um diálogo permanente fundamentado na alteridade, utilizando-se, para tanto, o emprego das abordagens êmica e ética que constituem a Etnomodelagem (ROSA; OREY, 2017). A ideia que representa o termo alteridade veiculase ao estado/qualidade de ser diferente, buscando-se nessa acepção 0 respeito à diversidade/pluralidade cultural por meio do convívio entre seus pares que se apresentam com características singulares - fato que "desencadeia-se a partir do reconhecimento da coexistência de muitas lógicas em um mesmo sistema", de modo que estas precisam interagir (ROSA; OREY, 2014, p. 141).

A análise e interpretação externa atribuída pelos outsiders (pesquisador, professor, aluno) que compõem a abordagem ética, traduzida em saberes matemáticos institucionalizados sobre os saberes construídos e os fazeres praticados pelos insiders, não devem sucumbir, tampouco, sobrepô-los. Devem confluir harmoniosamente de modo respeitoso e ético, uma vez que uma das intenções da Etnomodelagem, como já exposto, é reconhecer e dar visibilidade aos saberes dos grupos sociais minoritários que estão marginalizados pelo universo eurocêntrico. Em síntese,

[...] a abordagem êmica estuda as práticas matemáticas desenvolvidas internamente pelos membros de grupos culturais distintos, sendo localmente significativa enquanto a abordagem ética estuda essas práticas de acordo com o referencial cultural dos observadores externos. (CORTES, 2017, p. 47)

Afinal, os resquícios da educação jesuíta ainda persistem, sendo uma herança colonial que privilegia determinados saberes frente aos saberes dos povos e comunidades tradicionais: os povos indígenas, os ciganos, os quilombolas, as comunidades tradicionais de matriz africana ou de terreiro, os extrativistas, os ribeirinhos, os caboclos, os pescadores artesanais, entre outros.

Já a abordagem êmica se associa aos modus operandi3 como os insiders se relacionam entre si, produzindo, assim, uma transmissão de conhecimento que, perpetuada de geração a geração, consolida a cultura local. Isto é, essa faceta da Etnomodelagem está concatenada à visão que os membros de uma comunidade têm sobre seus próprios saberes-fazeres. Uma maneira subjetiva de compreender as relações que são estabelecidas entre si, dentro de seu lócus social.

Isso posto, destaca-se que a observância da Etnomodelagem sobre as atividades, em especial matemáticas, que são produzidas, desenvolvidas e difundidas por meio da linguagem formal e não formal

\footnotetext{
${ }^{3}$ Expressão oriunda do latim que significa "modo de operação".
} 
por gerações e gerações (manifestadas nas variadas ações do homem na resolução de situações do dia a dia), requer do etnomodelador eticidade na tradução da compreensão dos aspectos culturais inerentes a um grupo social sem, no entanto, interferir e/ou modificá-las.

A Etnomodelagem, com essas posições demarcadas por características antropológicas, promove no âmbito educacional a descentralização do conhecimento da figura do professor e compartilha essa responsabilidade com todos os envolvidos do/no processo de ensino e de aprendizagem de maneira participativa e ativa, promovendo, assim, a emancipação do estudante no processo enraizado em princípios dialógicos. Fato que contribui para que o mesmo assuma o papel de protagonista da sua própria aprendizagem.

Sob esses aspectos, Rosa e Orey (2012) destacam que a Etnomodelagem objetiva analisar e traduzir os fenômenos realizados nas relações dos grupos culturais locais em uma linguagem matemática, utilizando-se, para tanto, do conhecimento formal da mesma. Em outras palavras, a Etnomodelagem tem como enfoque os processos e o desenvolvimento de práticas que resultam em saberes matemáticos locais (ROSA; OREY, 2012). Para isso, alicerça-se nos princípios da Etnomatemática, que se trata "de um sistema de pensamento matemático sofisticado que não visa somente ao desenvolvimento das habilidades matemáticas, mas, sim, o entendimento do 'como fazer' matemática" (ROSA; OREY, 2003, p. 1), com o desenvolvimento da MM, a qual é

[...] essencial para o programa etnomatemática, pois as suas técnicas proporcionam a contextualização da matemática acadêmica ao fornecer as condições necessárias para que os indivíduos pertencentes a grupos culturais distintos adquiram as mesmas ferramentas educacionais utilizadas pela classe dominante para que possam atuar competitivamente na sociedade contemporânea e no mundo globalizado. (OREY; ROSA, 2018, p. 190)

Percebe-se uma singularidade entre a $M M$ e a Etnomatemática que, se utilizadas concomitantemente, resultam na Etnomodelagem, ou seja, "a aplicação da Etnomatemática em conjunto com as ferramentas da modelagem fornece por meio da Etnomodelagem uma visão holística do conhecimento matemático desenvolvido pelos membros de grupos culturais distintos" (ROSA; OREY, 2014, p. 132). Dessa forma, a Etnomodelagem é uma alternativa metodológica que visa compreender (e, posteriormente, formalizar) os conhecimentos matemáticos de diferentes grupos culturais, possibilitando que tal conhecimento ultrapasse as barreiras culturais e ideológicas locais.

\section{PERSPECTIVAS METODOLÓGICAS}

Na busca por subsídios para a análise, foi feita uma busca por produções acadêmicas sobre Etnomodelagem no Catálogo de Teses e Dissertações da Coordenação de Aperfeiçoamento de Pessoal 
de Nivel Superior (CAPES) e da Biblioteca Digital de Teses e Dissertações (BDTD). Essa pesquisa se aproxima do conjunto de características exploratórias descritas por Bogdan e Biklen (2010), inserindo-se na abordagem qualitativa interpretativa. Para tanto, utilizou-se os princípios que regem o Mapeamento na Pesquisa Educacional (MPE), segundo Biembengut (2008), para o desenvolvimento da mesma.

De acordo com Biembengut (2008), o MPE é um método voltado para o âmbito da educação, usado também para mapear trabalhos científicos que foram publicados sobre a temática utilizada pelo pesquisador. Utilizar a técnica do MPE, segundo a autora, envolve a realização de um conjunto de procedimentos, que se inicia com a identificação das informações associadas ao problema a ser pesquisado para, então, realizar um levantamento das pesquisas que permitem ao pesquisador obter informações sobre a problemática da qual se procura a resposta.

Assim, foi realizada uma análise exploratória de pesquisas no portal do Banco de Teses e Dissertações da CAPES e da BDTD que se fundamentam à luz da Etnomodelagem. A finalidade dessa ação foi identificar a existência de produções acadêmicas que se debrucem sobre a temática proposta nessa pesquisa, para posteriormente compreendê-las. A razão de escolher os repositórios Catálogo da CAPES e BDTD se traduz pelo fato de serem os maiores acervos de produções científicas do país, concentrando, portanto, as pesquisas de dissertações e teses.

Para a realização do método, utilizou-se o descritor "Etnomodelagem" no campo de busca na plataforma virtual da CAPES e da BDTD, resultando em cinco e quatro dissertações, respectivamente. Das quatro dissertações encontradas na BDTD três são duplicadas em relação às encontradas no portal da CAPES, diferenciando-se, apenas, a dissertação de Sonego (2009)4. Após essa busca, de acordo com Biembengut (2008), é necessário classificar e a organizar os dados (mediante a escolha de critérios); assim, há uma percepção mais evidente quanto à extração das informações pertinentes.

Com o intuito de atender a essa finalidade, alinhado com a percepção de aproximações dos resultados com o objetivo proposto neste estudo, foram utilizados como critérios de seleção das pesquisas os seguintes apontamentos: i) leitura do título; ii) leitura do resumo; iii) leitura das palavraschaves; e iv) leitura dos objetivos. Após a análise, descartou-se três dissertações por não se aproximarem de conceitos/abordagens que ancoram a Etnomodelagem segundo Rosa e Orey (2003; 2006; 2010; 2017; 2020). Assim, classificou-se de forma crescente os resultados filtrados em relação ao tempo de publicação, denominando-os de $T_{1}, T_{2}$ e $T_{3}$, de acordo com o quadro a seguir. Cabe destacar que todas as pesquisas são dissertações.

\footnotetext{
4 Dissertação intitulada "As contribuições da Etnomodelagem Matemática no ensino da geometria espacial". Disponível em: https://url.gratis/EQ6AC. Acesso em: 20 jan. 2021.
} 
Quadro 1: Relação dos trabalhos encontrados.

\begin{tabular}{|c|l|l|l|l|}
\hline Trabalho & \multicolumn{1}{|c|}{ Título } & \multicolumn{1}{|c|}{ Autor } & \multicolumn{1}{|c|}{ Instituição } & \multicolumn{1}{c|}{ Ano } \\
\hline$T_{1}$ & $\begin{array}{l}\text { O ENSINO DA GEOMETRIA COM O ENFOQUE NA } \\
\text { ETNOMODELAGEM }\end{array}$ & $\begin{array}{l}\text { Adriano Marcos } \\
\text { Maia Reges }\end{array}$ & UFERSA $^{5}$ & 2013 \\
\hline$T_{2}$ & $\begin{array}{l}\text { RE-SIGNIFICANDO OS CONCEITOS DE FUNÇÃO: UM } \\
\text { ESTUDO MISTO PARA ENTENDER AS CONTRIBUIÇÕES } \\
\text { DA ABORDAGEM DIALÓGICA DA ETNOMODELAGEM }\end{array}$ & $\begin{array}{l}\text { Diego Pereira } \\
\text { de Oliveira } \\
\text { Cortes }\end{array}$ & UFOP6 & 2017 \\
\hline$T_{3}$ & $\begin{array}{l}\text { ETNOMODELAGEM: UMA ABORDAGEM DE CONCEITOS } \\
\text { GEOMÉTRICOS NO CEMITÉRIO DE ARRAIAS }\end{array}$ & $\begin{array}{l}\text { Cristiane Castro } \\
\text { Pimentel }\end{array}$ & UFT7 $^{\text {Un }}$ & 2019 \\
\hline
\end{tabular}

Fonte: Os autores.

Para Biembengut (2008), após a realização dessa etapa de classificação e organização, que se constitui como parte integrante do procedimento do Mapeamento - Método de Análise, faz-se necessário, agora, compreender os dados de acordo com um conjunto de parâmetros pré-definidos.

\section{RESULTADOS DO MAPEAMENTO}

De acordo com Madruga et al. (2017), o mapeamento leva o pesquisador a ter uma visão panorâmica dos dados, possibilitando realizar uma análise dos mesmos. Assim, para verificar, analisar e compreender a seleção das pesquisas mapeadas, estabeleceram-se as seguintes categorias, a priori: i) Problema e objetivos (gerais e/ou específicos); e ii) Resultados das pesquisas e contribuições para a Educação Matemática. Na sequência, tecem-se considerações sobre os principais aspectos para cada categoria definida a priori.

\subsection{Problema e objetivos}

O trabalho $T_{1}$ apresenta a questão de pesquisa: "Quais são as possíveis contribuições da Modelagem Matemática na construção de conhecimentos de Geometria Espacial enquanto é explorado o tema Produção de doce em escala industrial?" (REGES, 2013, p. 34).

A pesquisa $T_{1}$ foi realizada com discentes do segundo ano do Ensino Médio de uma Escola Pública de um município do Estado do Ceará. O objetivo era analisar as contribuições do conhecimento da Geometria Espacial na indústria de alimentos, fazendo um paralelo com a produção de doces em

\footnotetext{
5 Universidade Federal Rural do Semiárido de Rio de Janeiro.

6 Universidade Federal de Ouro Preto.

7 Universidade Federal do Tocantins.
} 
escala comercial. Além disso, visava trabalhar situações do dia a dia para facilitar a apropriação dos conteúdos abordados.

A questão de investigação do trabalho $T_{2}$ restringe-se em investigar [...] quais são as possíveis contribuições que a etnomodelagem pode oferecer para o processo de re-significação de conceitos de funções para alunos do $2^{\circ}$ ano do ensino médio de uma escola pública da região metropolitana de Belo Horizonte por meio de sua abordagem dialógica? (CORTES, 2017, p. 23)

Cortes (2017, p. 24), em sua dissertação $\left(T_{2}\right)$, apresenta o objetivo geral do seu trabalho: "mostrar como a abordagem dialógica da Etnomodelagem pode contribuir para o processo de resignificação dos conceitos de função de alunos matriculados no segundo ano do ensino médio de uma escola pública na região metropolitana de Belo Horizonte". Mais especificamente:

[...] a) descrever a conexão entre a Etnomatemática e a Modelagem Matemática, b) compreender a importância das concepções culturais para a elaboração de etnomodelos matemáticos extraídos das práticas cotidianas encontradas no contexto sociocultural do feirante, c) descrever como as abordagens êmica, ética e dialógica da Etnomodelagem se manifestam durante os encontros entre um grupo de alunos do segundo ano do ensino médio e um feirante e d) verificar como as práticas matemáticas de um feirante podem ser utilizadas em sala de aula para o desenvolvimento da ação pedagógica para a Etnomodelagem. (CORTES, 2017, p. 24)

A condução dessa pesquisa está centrada na análise interpretativa da atividade profissional de um feirante com os estudantes de uma escola pública, tendo como suporte as abordagens da Etnomodelagem para, assim, entender os conteúdos matemáticos que emanam dessa prática, focando naqueles relacionados com a re-significação do conceito de funções.

A questão norteadora do trabalho $T_{3}$ foi "Quais são os etnomodelos geométricos presentes no muro do cemitério de Arraias e na praça de acolhimento?" (PIMENTEL, 2019, p. 20).

Pimentel $\left(2019\right.$, p. 10) traz como objetivo geral de sua pesquisa $\left(T_{3}\right)$ "identificar etnomodelos matemáticos presentes na construção do muro do Cemitério e sua praça de acolhimento da cidade de Arraias - TO, proporcionando o conhecimento de parte da realidade local". A autora discorre, ainda, que existe a intencionalidade de utilizar os conceitos da Etnomodelagem como alternativa metodológica nas aulas de Matemática, visando ressignificar a prática docente em serviço de um ambiente educacional mais propício à aprendizagem dos estudantes.

Observa-se que as questões dos trabalhos $T_{1}$ e $T_{3}$ apresentam pontos confluentes entre si em relação à unidade temática de geometria, por investigarem aspectos direcionados às construções geométricas presentes em um determinado espaço cultural de uma localidade, enquanto que a $T_{2}$ estuda outro objeto do conhecimento matemático (funções). Notabiliza-se, além disso, que em nenhuma das 
pesquisas supracitadas aparecem direcionamentos acerca da formação de professores e/ou desenvolvimento profissional do professor, visto que a dimensão de todas as pesquisas se concentra no processo de aprendizagem, possuindo como referência a Etnomodelagem.

É possível perceber que as pesquisas supramencionadas têm objetivos em comum, pois buscam possíveis contribuições para o ensino de Matemática de um determinado objeto de conhecimento por meio da Etnomodelagem. Visa-se nessas pesquisas a confecção de etnomodelos a partir dos procedimentos matemáticos utilizados na modelagem, em um contexto sociocultural onde se apresentam conceitos matemáticos contidos nas práticas diárias dos membros dos grupos sociais estudados, que são traduzidos para a linguagem matemática.

\subsection{Resultados das pesquisas e contribuições para a Educação Matemática}

Os indícios da pesquisa desenvolvida por Reges (2013) apontaram que houve um desempenho satisfatório no processo de aprendizagem dos discentes. O protagonismo estudantil no desenvolvimento das atividades foi sublinhado pois, nesse ambiente, os discentes produziram o seu próprio conhecimento de forma empírica a partir de sua motivação em atender o que fora proposto, demonstrando assim um engajamento significativo.

Essa proposta educacional conduz, segundo Reges (2013), a um processo onde a teoria estudada em sala de aula está em diálogo com a prática, fato que proporciona aos estudantes a possibilidade de compreender e resolver situações-problemas do cotidiano no qual estão inseridos. Por fim, sublinha o autor que nessa proposta metodológica a relação do professor e aluno ganha destaque, não cabendo mais ao professor ser o detentor do conhecimento, mas um mediador do processo educativo onde ambos, mutuamente, se ajudam em busca do conhecimento.

Na pesquisa $T_{2}$ Cortes (2017) concluiu que, no processo de ensino e aprendizagem, a Etnomodelagem é uma metodologia alternativa eficiente para o currículo de Matemática, pois carrega em si as abordagens êmica e ética, que possibilitam uma compreensão intuitiva e empática das práticas matemáticas dos membros de um determinado grupo cultural. Ou seja, a prática pedagógica pautada nessa perspectiva pode fornecer uma visão "mais completa sobre o conhecimento das práticas matemáticas desenvolvidas pelos membros dos grupos culturais distintos, como, por exemplo, a resignificação dos conceitos de função" (CORTES, 2017, p. 189).

Além disso, o autor ainda destaca que "[...] os resultados desse estudo mostraram que existe uma complementaridade nas relações existentes entre os membros de grupos culturais distintos com relação às ideias, aos procedimentos e às práticas matemáticas desenvolvidas localmente" (CORTES, 


\section{revemop}

2017, p. 189). Fato que reforça a ideia de que os saberes locais e os saberes consolidados pela academia interagem, não cabendo, portanto, a supremacia de um saber sobre o outro.

Um recorte da dissertação de Cortes (2017) é apresentado em Cortes, Rosa e Orey (2020), onde os autores apresentam resultados que mostram a Etnomodelagem propiciando a integração entre do currículo matemático escolar, considerando o conhecimento êmico e ético, por meio da abordagem dialógica, evidenciando a relevância do dinamismo cultural.

Por fim, Pimentel (2019) percebeu em seu estudo que os participantes envolvidos na construção de muros não se apropriaram de um conhecimento acadêmico, apenas dos saberes que aprenderam ao longo dos anos, com suas experiências e vivências. A autora destaca o descompasso entre o ensino de Matemática e a realidade do estudante, pois muitos objetos de conhecimento não são trabalhados de forma significativa nem são vinculados à sua realidade.

A autora aponta a necessidade de considerar os conhecimentos adquiridos e construídos pelas comunidades às quais os estudantes pertencem e reforça essa concepção ao apontar que "[...] esse conhecimento empírico unificado com o conhecimento que vão aprendendo em sala de aula pode tornar sua aprendizagem mais significativa e mais interessante" (PIMENTEL, 2019, p. 109).

Diante desse contexto, a pesquisa $T_{3}$ sugeriu como método de ensino aplicado à educação - 0 conceito da Etnomodelagem, apresentando-o como uma nova orientação curricular que propõe um ensino de Matemática voltado para o desenvolvimento de competências para o exercício pleno da cidadania, visto que em sua essência possui características que aproximam os saberes desenvolvidos por um grupo social/cultural dos saberes escolares, dialogando, assim, com "[...] suas tradições e crenças, seus costumes fazendo com que o aluno se sinta em um ambiente de aprendizagem que condiz com seus conhecimentos" (PIMENTEL, 2019, p. 98).

Dentre as pesquisas descritas anteriormente, percebe-se que essas estão fundamentadas principalmente na Etnomodelagem, segundo Rosa e Orey (2003; 2006; 2010; 2014), com exceção da pesquisa T1, que relaciona as conexões entre a MM e a Etnomatemática sem, no entanto, utilizar a abordagem êmica e ética (ou a dialógica, resultante da interação mútua entre essas). Porém, nenhuma enfocou em um processo formativo, apoiando-se na própria dimensão teórica para a condução do processo formativo.

A Etnomodelagem ainda está em fase de consolidação no Brasil, fato que justifica as poucas investigações acerca da temática. Existem pesquisas que apresentam a Etnomodelagem de forma implícita, a exemplo da investigação de Altenburg (2017) que, embora não explicite em seu título, resumo ou palavras-chaves o termo 'Etnomodelagem', utilizou-se dessa abordagem para nortear as ações de 
sua investigação. Alterburg (2017) alicerçou-se na perspectiva da Etnomodelagem e dos recursos advindos da Tecnologia da Informação e Comunicação (TIC) a fim de promover um resgate da cultura pomerana por meio da valorização dos traços presentes na arquitetura das construções, cujos detalhes contemplam as formas geométricas, que servem como agentes de promoção do ensino da Geometria.

É salutar destacar que há grupos que estão produzindo pesquisas nesta área, como a Universidade Federal de Ouro Preto - MG e a Universidade Estadual de Santa Cruz - BA. No ano de 2020, quatro dissertações que foram defendidas com o enfoque da Etnomodelagem nestas instituições de ensino se destacaram, mas não estão disponíveis ainda nos repositórios investigados, a saber: Dutra (2020); Eça (2020); Mesquita (2020); e Santos (2020).

Dutra (2020) procurou explicar como a aplicação da Etnomodelagem contribui para uma compreensão mais ampla dos conteúdos matemáticos e geométricos por meio de uma ação pedagógica relacionada com a cultura cafeeira. Mesquita (2020) realizou uma análise sociocrítica da Etnomodelagem enquanto ação pedagógica no desenvolvimento de conteúdos matemáticos em comunidades periféricas; Santos (2020) analisou o desenvolvimento de uma proposta de ensino, fundamentada na Etnomodelagem, para a construção de etnomodelos da produção artesanal de chocolate; e Eça (2020) investigou as possíveis implicações de uma formação continuada, fundamentada na Etnomodelagem, para o desenvolvimento profissional do professor que ensina Matemática.

Um recorte da dissertação de Santos (2020) é apresentado em Santos e Madruga (2021) onde os resultados mostraram que por meio dos etnomodelos êmicos, os participantes conseguiram criar etnomodelos gráficos e algébricos (éticos e/ou dialógicos) para representar a produção de chocolate artesanal da fábrica. Esses resultados vêm ao encontro do que declara Pradhan (2020), sobre artefatos culturais familiares aos estudantes, os quais, segundo o autor, auxiliam na mediação para comunicar ideias abstratas da Matemática, ajudando na aprendizagem de conceitos matemáticos.

Percebe-se que a maioria das pesquisas tem como foco o ensino e aprendizagem de Matemática por meio da Etnomodelagem. Exceto a pesquisa de Eça (2020), que contempla a formação do professor, mostrando interesse em realizar um processo formativo para professores tendo como base teórica a Etnomodelagem (ROSA; OREY, 2003). Com efeito, tal formação continuada resultou na dissertação intitulada "Formação continuada à luz da Etnomodelagem: implicações para o desenvolvimento profissional do professor que ensina matemática", que envolveu todos os professores que lecionavam 0 componente de Matemática no município de Taperoá-BA, no ano da realização da pesquisa (EÇA, 2020).

Um desdobramento dessa pesquisa, intitulada "Formação continuada à luz da Etnomodelagem: construção de uma proposta de ensino com professores que ensinam matemática no ensino 
fundamental", focou na construção de uma proposta de ensino (uma das etapas da investigação) fundamentada na Etnomodelagem (EÇA; PEIXOTO: MADRUGA, 2021).

\section{DISCUSSÕES SOBRE ETNOMODELAGEM E FORMAÇÃO DE PROFESSORES}

A pesquisa de Eça (2020) buscou responder à seguinte questão: "Quais as possíveis implicações que uma formação continuada, fundamentada na Etnomodelagem, pode trazer para o desenvolvimento profissional do professor que ensina Matemática?", tendo como objetivo "Investigar as possíveis implicações que uma formação continuada, fundamentada na Etnomodelagem, pode trazer para 0 desenvolvimento profissional do professor que ensina Matemática" (EÇA, 2020, p. 24).

A análise da pesquisa de Eça (2020) instiga muitas reflexões com relação à Etnomodelagem e à formação de professores. Percebeu-se o desconhecimento dos docentes envolvidos na pesquisa em relação a esta alternativa metodológica, bem como as noções superficiais sobre a Etnomatemática e a Modelagem Matemática. Para completar essa lacuna, deve-se investir na formação inicial e continuada de professores, pois estes espaços são uma oportunidade para ressignificar os conceitos já vistos, visando a construção de uma nova abordagem, que pode se constituir como uma nova maneira de conceber a Matemática. Para isso, faz-se necessário se desconectar do modus operandi de ensinar Matemática sob as raízes tradicionais, na qual impera a centralização da construção do saber matemático sob as lentes hegemônicas.

Assim, abre-se um leque de oportunidades de se construir saberes matemáticos pautados nos fazeres culturais que estão à luz, porém, ocultos para os olhares rígidos, carregados de preconceitos. Aqui, tais visões são denominadas de cancelamento matemático da produção dos saberes-fazeres oriundos dos grupos sociais marginalizados, pertencentes às classes minoritárias. Destaca-se que cada grupo cultural possui aspectos peculiares no tratamento das situações-problemas oriundas da interação com o meio, que está carregado de saberes matemáticos.

As abordagens da Etnomodelagem se fecundam a partir da construção do saber matemático do/no seio cultural das classes oprimidas, servindo de ferramenta sociopolítica para os membros desses grupos que são invisibilizados pela sociedade, que por sua vez foi historicamente doutrinada a reconhecer e valorizar, quase que unicamente, os saberes oriundos da Europa: os saberes hegemônicos, afogando, dessa forma, toda e qualquer caravela pensante que navegue em outros mares.

Assim, a corrente teórica que sustenta a Etnomodelagem, que perpassa pela interseção e interação dinâmica entre o Programa de pesquisa da Etnomatemática, da Modelagem Matemática e da Antropologia Cultural, é símbolo de resistência no âmbito educacional, posto que, imbuído da 
dialogicidade, serve de achatamento para as curvas sinuosas que simbolizam os saberes locais e globais, que por vezes caminham em lados opostos ao invés de paralelas ou próximas.

O processo conduzido pela abordagem dialógica permite que os diferentes saberes, traduzidos pelas abordagens êmicas e éticas, desenvolvam-se de modo simétrico e com alteridade. A região formada pela aproximação das abordagens éticas e êmicas, intermediada pela dialogicidade, entendida, aqui, como a zona dialógica, prevê a promoção e desenvolvimento da justiça, cidadania, equidade e demarca um território de enfrentamento a qualquer forma de soberania intelectual de um povo sobre outro. De acordo com essa aspiração, Eça (2020) representa um esboço dessa ideia por meio da seguinte ilustração:

Figura1: As curvas de aproximação às abordagens êmicas e éticas

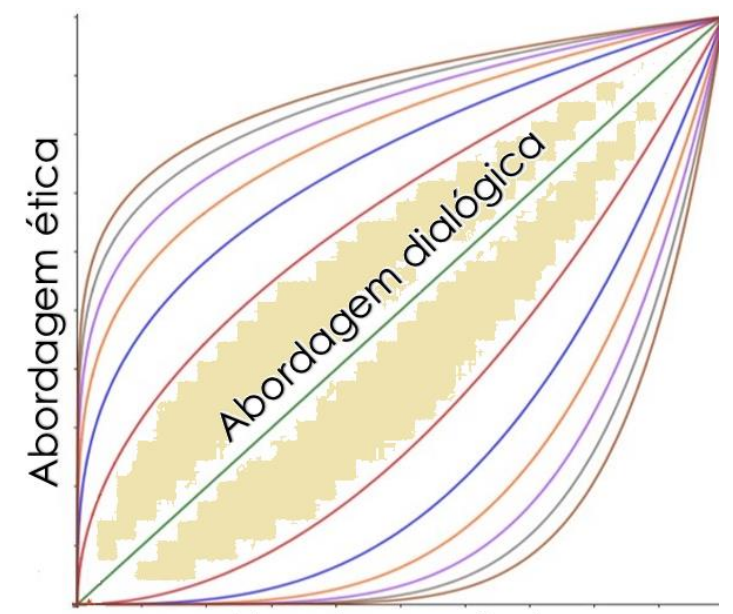

Abordaaem êmica

Fonte: Adaptado (EÇA, 2020, p. 81).

Endossar o distanciamento desses saberes é, de certo, fortalecer a soberania de um sobre 0 outro. Isso, em outras palavras, é valorizar erroneamente um lado da moeda sobre o outro, mesmo sabendo que ambos os lados pertencem ao mesmo material. Refutar esse cenário, e do contrário, aproximar as regiões compreendidas entre os saberes locais e globais, significa horizontalizar em um mesmo degrau ambos sem, no entanto, homogeneizá-los (EÇA, 2020). Essa compreensão permite, por meio das abordagens êmica e ética, fundamentadas pela dialogicidade, que os indivíduos de um determinado grupo traduzam, troquem e produzam saberes e a partir desses construam outros saberes em um movimento transcultural. Com isso, algumas heranças culturais se desvanecem, pois a incorporação transcultural é acompanhada de efeitos de rompimento das barreiras culturais. Assim:

No processo da etnomodelagem, os construtos êmicos são as narrativas, as descrições e as análises das ideias, procedimentos e práticas matemáticas que são expressas em termos dos esquemas e categorias conceituais que são consideradas apropriadas e significativas pelos membros do grupo cultural. (ROSA; OREY, 2014, p. 137) 
Sob esse prisma, os membros que estão inseridos nessa localidade mobilizam saberes por meio do processo da transculturalidade, visando, especialmente, valorizar seu espaço e, a partir dele, suas tradições, costumes, valores, bem como os conhecimentos matemáticos manifestados, o que independe de sua localização geográfica, histórica, social e cultural (ROSA; OREY, 2017).

Esse entendimento faz com que as pesquisas ancoradas na Etnomodelagem descortinem "[...] ideias, noções, procedimentos e práticas matemáticas distintas por meio de valorização e do respeito aos conhecimentos adquiridos quando os indivíduos interagem com o próprio ambiente" (ROSA; OREY, 2014, p. 20).

A pesquisa de Eça (2020) consistiu na realização de uma formação continuada com 11 professores dos anos finais do Ensino Fundamental do Sistema de Ensino do município de TaperoáBahia. A formação foi realizada em seis momentos/turnos de quatro horas cada, totalizando 24 horas. Como instrumentos de produção de dados, foram utilizados o diário de campo, a gravação em áudio, a observação, o questionário e a entrevista semiestruturada. Após a realização da análise dos dados, ancorada na Análise Textual Discursiva (ATD), emergiram quatro categorias, a saber: Processo formativo (1), Docência (2), Currículo (3) e Abordagem dialógica (4) (EÇA, 2020).

A primeira categoria (Processo formativo) surgiu pelo sentido que representou a formação para os participantes, uma vez que essa foi de encontro com as formações comumente realizadas no município: costuradas sob moldes tradicionais, revestidas da racionalidade técnica e maquiadas com 0 fazer dicotômico entre teoria e prática. Ao contrário disso, as ações propiciaram envolver os participantes a partir do contexto sociocultural ou profissional no qual interagem, o que gerou motivação e um sentimento de pertencimento em relação ao processo como um todo.

Afinal, o currículo engessado não contempla, reconhece ou valoriza os saberes-fazeres que não sejam os já sistematizados pela academia, efeito que gera um processo excludente e/ou de (super)valorização do conhecimento formal sobre os nascidos dos grupos sociais. Além do exposto, destaca-se, também, nessa categoria, a construção coletiva com viés colaborativo, cenário formativo que promoveu uma práxis docente. Tônica essa que tendenciou uma maior participação do professor no processo, possuindo, assim, uma emancipação nas narrativas que se associavam ao contexto sociocultural que estão inseridos.

Em relação à segunda categoria (Docência), foi se constituindo a partir da ruptura do individualismo docente, que deu espaço ao diálogo que regeu todas as ações formativas. Isso descaracteriza, por consequência, a visão fragmentada do conhecimento que incide, ainda, no currículo. 
Pensar de modo contrário é aproximar-se da perspectiva interdisciplinar que mobiliza, em um ambiente educativo, diferentes saberes para a aquisição da aprendizagem sob o viés integrador.

Traz-se à tona, nessa categoria, a discussão que traduz uma ruptura com o sistema hierarquizado do conhecimento que é expresso no modelo curricular tradicional, na qual os saberes são separados e isolados em blocos do conhecimento. Essa visão fragmentada do saber não possibilita, por exemplo, cunhar as abordagens da Etnomodelagem, uma vez que essas estão pautadas pela transculturalidade, isto é, visa-se a construção do saber a partir da pluralidade em que as relações sociais se apresentam e se constituem.

O movimento educacional dinâmico, participativo e ativo dos agentes educacionais que envolve o processo de ensino e de aprendizagem que propõe as abordagens da Etnomodelagem, que visa convergir para a zona dialógica, requer utilizar as relações socioculturais e fazer de tal ambiente a própria sala de aula, um laboratório do saber que carrega múltiplas facetas do conhecimento que pode ser traduzido para uma linguagem matemática e por meio dela interligar saberes plurais. Assim, a Etnomodelagem enfrenta o currículo rígido, estabelecendo conexões flexíveis na/para a construção do saber, que pelas vias tradicionais talvez não aconteçam.

A garimpagem dos saberes extraescolares, via as abordagens que fundamentam a Etnomodelagem, descortiça não apenas a tradução de saberes para a linguagem matemática, mas desvela saberes ofuscados que, de certo modo, não são contemplados pelo currículo colonizado, interligado às correntes europeias (hegemônicas). Oportunidade, inclusive, de utilizar a Etnomodelagem como instrumento de emancipação social para os grupos sociais que ainda são subordinados ao sistema opressor. A emancipação do sujeito, por meio da Etnomodelagem, alia-se à perspectiva de tornar 0 conhecimento matemático a serviço do desenvolvimento cidadão, autêntico e em prol do empoderamento do povo marginalizado.

Revelou-se na terceira categoria (Currículo) a dependência do professor em relação ao livro didático, visto que isso pode ocasionar uma estruturação inflexível na prática docente, valorizando mais os objetos de conhecimento do que as habilidades de sua construção. Cenário esse que muda com a utilização da Etnomodelagem, uma vez que a proposta de ensino que se fundamenta nessa dimensão teórica parte de um contexto sociocultural (Etnomatemática), possuindo como ferramenta a Matemática (MM).

Inclusive, a concepção atribuída ao currículo pelos participantes ora perpassava pelo livro, ora se concentrava no próprio livro. Nessa linha, Macedo (2007) chama a atenção para o fato de que, às 


\section{revemop}

vezes, os elementos que compõem o âmbito escolar são confundidos com o próprio currículo, embora assumir essa postura signifique limitar a dimensão vasta que o currículo assume.

À luz da Etnomodelagem, a formação continuada revelou, também, além do distanciamento do livro, uma busca por outras fontes, inclusive no contexto sociocultural. Aliás, é nele, no contexto sociocultural, que emana diferentes formas de matematizar, de modo que este deve ser mais explorado. Afinal, a realidade do discente não se traduz em uma linguagem matemática, mas carrega em si amplos e distintos significados tanto para os outsiders quanto para os insiders.

Essa mudança de postura e de perspectiva quanto às ações destinadas ao ensino de Matemática provocaram maior interação, reconhecimento e valorização dos saberes que são constituídos fora dos muros da escola, interligando, assim, segundo Eça (2020), os saberes globais e locais da zona dialógica.

A última categoria (Abordagem dialógica) se constitui por meio da aproximação das propostas de ensino elaboradas com as distintas facetas que representam a realidade do discentes. A intencionalidade de se inserir no contexto do discente a fim de traduzir os saberes-fazeres para a linguagem matemática perpassa, sobremodo, por outros fatores que apenas o conhecimento matemático, por si só, não é suficiente. Representa uma válvula de entrada para a imersão para outros engendramentos que devem ser explorados, também, nas aulas de Matemática, como: desigualdade social, feminicídio, relações étnico raciais, intolerância religiosa, fome, direitos humanos, drogas, vulnerabilidade social, etc. Afinal, são fatores que não estão desligados quando os discentes saem desse contexto, ao irem ou chegarem da escola; são aspectos que estão presentes e confluem com suas vidas.

A Matemática, nesse contexto, por meio da Etnomodelagem, torna-se uma aliada na compreensão de mundo de modo crítico. A união entre os saberes globais e locais é importante, mas não pode ser vista como a solução. É necessário, numa reciprocidade dinâmica, diluir as arestas que carregam visões de supremacia entre grupos sociais ou classes. Assim, a zona dialógica, resultado de uma prática pedagógica que se baseia na relação simbiótica das abordagens êmicas e ética, reflete os contextos socioculturais sob uma lente transcultural que reconhece, valoriza e dá sentido aos saberes ofuscados socialmente, por meio da Matemática.

Assim, a abordagem dialógica, provida da interação das abordagens êmicas e éticas, que se completam entre si, traz à tona as manifestações matemáticas das situações socioculturais que estão presentes no dia a dia, carregadas de saberes globais e locais que precisam ser inseridos no contexto escolar (currículo). Dessa forma, quem sabe, haverá a diminuição da opressão e das injustiças sociais que sofrem os membros dos grupos sociais por seu modo de lidar com os problemas do cotidiano. 
Dada a relevância das pesquisas apresentadas, notabiliza-se que, entre as distinções entre as mesmas, destaca-se que Eça (2020) traz um debate da Matemática com a fundamentação da Etnomodelagem interligada aos contextos socioculturais, voltando o olhar para a formação do professor que ensina matemática.

\section{CONSIDERAÇÕES FINAIS}

Este artigo objetivou apresentar uma análise crítica a partir do aprofundamento teórico sobre Etnomodelagem e do mapeamento de pesquisas recentes. Constatou-se que ainda não existem formações continuadas à luz da Etnomodelagem localizadas no Catálogo de Teses e Dissertações da CAPES e na BDTD. No entanto, embora não esteja disponível nessas plataformas virtuais, existe a pesquisa de Eça (2020), que apresenta uma formação continuada com os professores que ensinam matemática na cidade de Taperoá-BA, à luz da Etnomodelagem.

A reestruturação dos currículos horizontais a todos os entes federativos, alinhada aos preceitos da BNCC, deve levar em consideração os saberes que são produzidos em setores da sociedade que estão marginalizados e ocultos sob seu olhar. É necessário dar visibilidade e voz a tais produções, pois, caso contrário, a escola acaba sendo um espaço de cumplicidade a essas exclusões/injustiças sociais. O compromisso social e político cunhado em sua base deve fazer da escola um ambiente autocrítico, para que, assim, reflexões sobre seu currículo aconteçam.

Nessa corrente de pensamento, a Etnomodelagem ganha espaço, pois candidata-se como alternativa metodológica que utiliza o conhecimento formal da Matemática (por meio da MM) em favor de pautas socioculturais inerentes aos diversos grupos sociais. Sentido esse que leva à motivação do estudante para a construção da aprendizagem, uma vez que as abordagens da Etnomodelagem buscam, por meio da utilização da Etnomatemática e das técnicas da MM, traduzir - em etnomodelos situações-problemas locais identificadas no contexto sociocultural dos estudantes. Tradução que está carregada de significados que perpassam os conceitos apenas dos objetos matemáticos e transcendem a características transculturais (ROSA; OREY, 2017).

A Etnomodelagem, nessa conjuntura, oferece-se como instrumento político-pedagógico para estudar os fenômenos sociais de modo empírico a partir do prisma matemático, engajando, dessa maneira, os estudantes a refletirem os caminhos históricos que os constituem como membros de grupos sociais minoritários. 0 engajamento a essas discussões pode deflagrar no estudante símbolos de resistência contra o sistema, que normalmente é opressor sobre eles. 
Nesse contexto, de acordo com Ponte (1999), a formação do professor como educador ganha destaque, uma vez que a formação envolve uma esfera política e carregada de ideologias. Portanto, exige-se do profissional da educação compromisso social e uma reflexão contínua sobre a sua prática, tendo como base uma investigação empírica sobre sua formação. Um ciclo inacabado, mas em constante aperfeiçoamento na busca por uma educação equitativa, inclusiva, democrática e justa.

Posto a relevância do compromisso político-social do professor, alinhado aos preceitos ideológicos, conceituais e políticos que sustentam a base teórica da Etnomodelagem que, inclusive, está integrada aos pressupostos definidos nos documentos oficiais da educação brasileira, é pertinente haver formações continuadas à luz dessa alternativa metodológica, sobremodo para contribuir com o sistema educacional, diminuindo as desigualdades que ainda pairam sobre a sociedade e estão diariamente nas manchetes dos principais veículos de comunicação do país. Ressalta-se a importância de utilizar como mecanismo os saberes que ecoam nos/pelos territórios oprimidos que são camuflados, invisibilizados e terrivelmente marginalizados por uma sociedade que tem como espelho um outro território que está localizado no outro lado do Oceano Atlântico, a Europa.

Urge, então, a necessidade de reverter prioridades sociais, assim como está acontecendo na educação, atribuindo o direito a aprendizagem a todos(as) de modo equitativo. Sob essa lente social, a formação continuada sob a fundamentação da Etnomodelagem ganha protagonismo e candidata-se a instrumento no combate aos cenários que se distanciam da justiça social. Cenários que precisam ser fomentados nas pesquisas científicas.

\section{REFERÊNCIAS}

ALTENBURG, G. S. Contextualizando Cultura e Tecnologias: Um Estudo Etnomatemático Articulado ao Ensino de Geometria. 2017. Dissertação (Mestrado Profissional em Ensino de Ciências e Matemática) - Universidade Federal de Pelotas, Pelotas, 2017. Disponivel em: http://guaiaca.ufpel.edu.br/handle/prefix/3784. Acesso em: 10 mar. 2021.

BAHIA. Secretaria da Educação. Superintendência de Políticas para Educação Básica. União Nacional dos Dirigentes Municipais da Bahia. Documento curricular referencial da Bahia para educação infantil e ensino fundamental. 475p., 2019. Disponível em:

http://escolas.educacao.ba.gov.br/sites/defaultffiles/private/midiateca/documentos/2020/documentocurri cularbahia.pdf. Acesso em: 8 jan. 2021.

BIEMBENGUT, M. S. Mapeamento na Pesquisa Educacional. Rio de janeiro: Ciência Moderna, 2008. BOGDAN, R.; BIKLEN, S. Investigação Qualitativa em Educação. Porto: Porto, 2010. 
BRASIL. Base Nacional Comum Curricular. 3. versão. Brasília: MEC, 2017. Disponível em: http://basenacionalcomum.mec.gov.br/images/BNCC_EI_EF_110518_versaofinal_site.pdf. Acesso em: 18 jan. 2021.

BRASIL. Lei de Diretrizes e Bases da Educação. Lei n. 9.394/1996. Disponível em: https://www.planalto.gov.br/ccivil 03/Leis/L9394.htm. Acesso em: 28 jan. 2020.

BRASIL. Secretaria de Educação Fundamental. Parâmetros Curriculares Nacionais: Matemática. Brasília: MEC/SEF, 1998. Disponível em: http://portal.mec.gov.br/seb/arquivos/pdf/livro03.pdf. Acesso em: 8 set. 2020.

BRASIL. Base Nacional Comum Curricular. 3. versão. Brasília: MEC, 2017. Disponível em: http://basenacionalcomum.mec.gov.br/images/BNCC_EI_EF_110518_versaofinal_site.pdf. Acesso em: 8 fev. 2021.

BRASIL. Ministério da Educação. Diretoria de Avaliação da Educação Básica. Relatório Brasil no PISA 2018. 2019. Disponível em: https://download.inep.gov.br/acoes internacionais/pisa/documentos/2019/relatorio PISA 2018 prelimin ar.pdf. Acesso em: 10 jan. 2021.

CALDEIRA, A. D. Modelagem Matemática: um outro olhar. Alexandria Revista de Educação em Ciência e Tecnologia, Florianópolis, v.2, n.2, p. 33-54, 2009. Disponível em: https://periodicos.ufsc.br/index.php/alexandria/article/view/37940. Acesso em: 14 mar. 2021.

CORTES, D. P. O. Re-significando os conceitos de função: um estudo misto para entender as contribuições da abordagem dialógica da Etnomodelagem. 2017. 225 f. Dissertação (Mestrado Profissional em Educação Matemática) - Instituto de Ciências Exatas e Biológicas, Universidade Federal de Ouro Preto, Ouro Preto. Disponível em: https://www.repositorio.ufop.br/handle/123456789/8279. Acesso em: 8 set. 2020.

CORTES, D. P. DE O.; OREY, D. C. Connecting Ethnomathematics and Modelling: a mixed methods study to understand the dialogic approach of Ethnomodelling. Revemop, v. 2, p. e202011, 2020. DOI: https://doi.org/10.33532/revemop.e202011

D'AMBROSIO, U. Ethnomathematics: past and future. Revemop, v. 2, p. e202002, 2020. DOI: https://doi.org/10.33532/revemop.e202002

DUTRA, E. D. R. Etnomodelagem e café: propondo uma ação pedagógica para a sala de aula. 2020. Dissertação (Mestrado em Educação Matemática) - Instituto de Ciências Exatas e Biológicas, Universidade Federal de Ouro Preto, Ouro Preto, 2020.

EÇA, J. L. M. Formação continuada à luz da Etnomodelagem: implicações para o desenvolvimento profissional do professor que ensina matemática. 2020. Dissertação (Mestrado em Educação em Ciências e Matemática) - Universidade Estadual de Santa Cruz, Ilhéus, 2020.

EÇA, J. L. M.; PEIXOTO, J. L. B.; MADRUGA, Z. E. F. Formação continuada à luz da Etnomodelagem: construção de uma proposta de ensino com professores que ensinam Matemática no Ensino Fundamental. REAMEC - Rede Amazônica de Educação em Ciências e Matemática, [S. I.], v. 9, n. 1, p. e21005, 2021.

FREIRE, Paulo. Pedagogia da esperança: Um reencontro com a pedagogia do oprimido. Rio de Janeiro: Paz e Terra, 1992. 
FREIRE, P. Pedagogia da autonomia: Saberes necessários à prática educativa. São Paulo: Paz e Terra, 1996.

MACEDO, R. S. Currículo: Campo, conceito e pesquisa. Petrópolis: Vozes, 2007, p. 140.

MADRUGA, Z. E. de F.; SCHELLER, M.; CHAMOSO, J. M.; BREDA, A. Mapeamento de pesquisas em Modelagem Matemática na Espanha: recorte de produções científicas. Revista Intersaberes, v. 12, n. 26, p. $322-335, \quad 2017.20$ Disponível https://revistas.uninter.com/intersaberes/index.php/revista/article/view/1159. Acesso em: 04 jan. 2021.

MORIN, E. Os princípios do conhecimento pertinente. In: MORIN, E. Os sete saberes necessários à educação do futuro. São Paulo: Cortez, 2000.

MESQUITA, A. P. S. S. Uma análise sociocrítica da etnomodelagem como uma ação pedagógica para o desenvolvimento de conteúdos matemáticos em uma comunidade periférica. 2020. Dissertação (Mestrado em Educação Matemática) - Instituto de Ciências Exatas e Biológicas, Universidade Federal de Ouro Preto, Ouro Preto, 2020.

OREY, D. C.; ROSA, M. Explorando uma abordagem dialógica da etnomodelagem: Traduzindo 0 conhecimento matemático local e global a partir de uma perspectiva sociocultural. Jornal Latinoamericano de Etnomatemática, [S. I.], v. 11, n. 1 p. 179-210, 2018. Disponível em: https://www.revista.etnomatematica.org/index.php/RevLatEm/article/view/485. Acesso em: 8 fev. 2021.

PIMENTEL, C. C. Etnomodelagem: uma abordagem de conceitos geométricos no cemitério de Arraias - TO. 2019. 109 f. Dissertação (Mestrado Profissional em Matemática) - Universidade Federal Do Tocantins, Arraias. Disponível em: http://repositorio.uft.edu.br/handle/11612/1372. Acesso em: 8 set. 2020.

PONTE, J. P. Didácticas específicas e construção do conhecimento profissional. In: TAVARES, A; PEREIRA, A. P.; SÁ, H. A. (Org.). Investigar e formar em educação. IV CONGRESSO DA SPCE. Actas [...], p. 59-72, Porto: SPCE, 1999. Disponível em: http://www.educ.fc.ul.pt/docentes/jponte/docs-pt/99Ponte(Aveiro).pdf. Acesso em: 8 set. 2020.

PRADHAN, J. B. Cultural artefacts as a metaphor to communicate mathematical ideas. Revemop, v. 2, p. e202015, 2020. DOI: https://doi.org/10.33532/revemop.e202015

REGES, A. M. M. $O$ ensino da geometria com enfoque na Etnomodelagem. 2013. 116 f. Dissertação (Mestrado em Educação Matemática) - Departamento de Ciências Exatas e Naturais, Universidade Federal Rural do Semi-Árido, Mossoró. Disponível em: encurtador.com.br/asBFV. Acesso em: 8 set. 2020.

ROSA, M.; OREY, D. C. O campo de pesquisa em Etnomodelagem: as abordagens êmica, ética e dialética. Educação e Pesquisa, São Paulo, v. 38, n. 04, p. 865-879, out./dez. 2012. Disponível em: https://www.scielo.br/pdf/ep/v38n4/06.pdf. Acesso em: 8 set. 2020.

ROSA, M.; OREY, D. C. Etnomodelagem: a abordagem dialógica de saberes e técnicas êmicas e éticas. Contexto \& Educação, ljuí, RS, v. 29, n. 94, p. 132-152, set/dez. 2014. Disponível em: https://www.revistas.unijui.edu.br/index.php/contextoeducacao/article/view/3110. Acesso em: $3 \mathrm{dez}$. 2020. 
ROSA, M.; OREY, D. C. Vinho e queijo: etnomatemática e modelagem. Bolema, Rio Claro, SP, v. 16, n. 20, p. 1-16, 2003. Disponível em: http://matpraticas.pbworks.com/w/file/fetch/108830845/10541-563081-PB.pdf. Acesso em: 8 set. 2020.

ROSA, M; OREY, D. C. Etnomodelagem: a arte de traduzir práticas matemáticas locais. São Paulo. Editora Livraria da Física, 2017.

ROSA, M.; OREY, D. C. Abordagens atuais do programa etnomatemática: delineando um caminho para a ação pedagógica. Bolema, v. 19, n. 26, 2006. p. 19-48.

ROSA, M.; OREY, D. C. Alho e sal: etnomatemática com modelagem. Perspectivas da Educação Matemática, v. 2, n. 4, 2010a. p. 149-162.

ROSA, M.; OREY, D. C. Etnomodelagem como um movimento de globalização nos contextos da etnomatemática e da modelagem. Com a Palavra, o Professor, v. 5, n. 11, p. 258-283, 29 abr. 2020. Disponível em: http://revista.geem.mat.br/index.php/CPP/article/view/565. Acesso em: 8 set. 2020.

SANTOS, J. Produção Artesanal de Chocolate e Etnomodelagem: construção do conceito de função por estudantes do Ensino Fundamental. 2020. Dissertação (Mestrado em Educação Matemática) Universidade Estadual de Santa Cruz, 2020.

SANTOS, J.; MADRUGA, Z. Etnomodelagem e produção artesanal de chocolate: uma investigação no $9^{\circ}$ ano do Ensino Fundamental. Revista de Ensino de Ciências e Matemática, v. 12, n. 1, p. 1-20, 18 mar. 2021.

SONEGO, G. V. As contribuições da Etnomodelagem matemática no estudo da geometria espacial. 2009. Dissertação (Mestrado Profissionalizante em Ensino de Física e Matemática) - UNIFRA: Centro universitário Franciscano, Santa Maria, 2009.

SCANDIUZZI, P.P. Água e Óleo: Modelagem e Etnomatemática? BOLEMA, Rio Claro, n. 17, p. 52-58, 2002. Disponível em: http://www.periodicos.rc.biblioteca.unesp.br/index.php/bolema/article/view/10604. Acesso em: 8 set. 2020. 